\title{
Evaluation of Anti-Inflammatory and Anti-Proliferative Effect of Hydroxy-, Keto-, and Epoxy-Carotenoids in RAW 264.7 and HL-60 Cells
}

Kariyappa Vijay, Poorigali Raghavendra-Rao Sowmya, Bangalore Prabhashankar Arathi and Rangaswamy Lakshminarayana*

Department of Biotechnology, Jnana Bharathi Campus, Bangalore University, Bengaluru-560 056, Karnataka, India

Correspondence to:

Rangaswamy Lakshminarayana

Department of Biotechnology

Jnana Bharathi Campus, Bangalore University

Bengaluru-560 056, Karnataka, India

Tel: +91-080-22961461

Fax: +91-080-23211020

E-mail: rlnarn21@gmail.com

Received: June 15, 2016

Accepted: September 13, 2016

Published: September 15, 2016

Citation: Vijay K, Sowmya PR, Arathi BP, Lakshminarayana R. 2016. Evaluation of AntiInflammatory and Anti-Proliferative Effect of Hydroxy-, Keto-, and Epoxy-Carotenoids in RAW 264.7 and HL-60 Cells. J Food Chem Nanotechnol 2(3): 153-161

Copyright: (C) 2016 Vijay et al. This is an Open Access article distributed under the terms of the Creative Commons Attribution 4.0 International License (CC-BY) (http://creativecommons. org/licenses/by/4.0/) which permits commercial use, including reproduction, adaptation, and distribution of the article provided the original author and source are credited.

Published by United Scientific Group

\begin{abstract}
Aim of the study was to investigate efficiency of hydroxy (lutein, LUT), Keto- (astaxanthin, AST) and epoxy- (fucoxanthin, FUCO) carotenoids on molecular/biochemical events in proliferation of RAW 264.7 and HL-60 cells. Lipopolysaccharide (LPS) induced RAW 264.7 cells treated either with $20 \mu \mathrm{M}$ of LUT or AST or FUCO or without carotenoid for $12 \mathrm{~h}$, and studied their differential influence on toxicity, inflammatory markers and nuclear factor- $\kappa \mathrm{B}$ p65 (NF- $\kappa$ B p65) expression levels. Similarly, HL-60 cells treated for $48 \mathrm{~h}$ and evaluated cytotoxicity and apoptosis inducing activity. It was observed, carotenoids treatment decreased cytotoxicity of LPS induced inflammation in macrophages. Among carotenoids, FUCO protects cytotoxicity by 10.7 and $15.8 \%$ than AST and LUT, respectively. Likewise, carotenoids treatments reduced Nitric oxide (NO), Prostaglandin $\mathrm{E}_{2}\left(\mathrm{PGE}_{2}\right)$ and NF- $\kappa \mathrm{B}$ p65 levels than LPS treated group, while FUCO shown to be superior to control markers of inflammation than AST and LUT. Similarly, in case of HL-60 cells, FUCO significantly reduced cell viability by 16.4 and $33.4 \%$ than AST and LUT, respectively. Further, increased apoptosis of HL-60 positively correlates with decreased glutathione, and increased malondialdehyde and oxidative stress in cells treated with FUCO than AST and LUT. Also, typical apoptotic morphological changes were observed in FUCO treated cells than other oxygenated carotenoids. These differences among oxygenated carotenoids may be due to functional group and reactivity with the cells. Further, we presumed that an increase in the number of oxygen or hydroxyl groups in the carotenoids may decide the bioactivity. This study provides a greater insight of oxygenated carotenoids to combat chemoprevention of cancers originating from inflammation.
\end{abstract}

\section{Keywords}

Astaxanthin, Lutein, Fucoxanthin, Cytotoxicity, Anti-inflammation, Antiproliferation

\section{Abbreviations}

AST: Astaxanthin; AO: Acridine orange; DMEM: Dulbecco's modified eagle's medium; DMSO: Dimethyl sulfoxide; DCF: 2'-7'-dichlorofluoresceindiacetate; DTNB: 5, 5-dithiobis (2-nitrobenzoic acid); EtBr: Ethidium bromide; FBS: Fetal bovine serum; FUCO: Fucoxanthin; GR: Glutathione reductase; HRP: Horseradish peroxidase; LUT: Lutein; LPS: Lipopolysaccharide; MDA: Malondialdehyde;MTT:3-[4,5-dimethylthiazol-2-yl]-2,5-diphenyltetrazolium bromide; NAD: Nicotinamide adenine dinucleotide; NADPH: Nicotinamide adenine dinucleotide phosphate oxidase; NO: Nitric oxide; NF-кB p65: Nuclear factor-KB p65; PBS: Phosphate buffered saline; $\mathrm{PGE}_{2}$ : Prostaglandin $\mathrm{E}_{2}$; PI: 
Propidium iodide; ROS: Reactive oxygen species; RPMI 1640: Roswell park memorial institute; TMP:Tetramethoxypropane; LDH: Lactate dehydrogenase

\section{Introduction}

Carotenoids are synthesized de novo majorly by plants and certain microorganism including algae. In nature, more than 700 carotenoids are found and classified as carotenes (hydrocarbon carotenoids) and xanthophylls (oxygenated carotenoids). Dietary carotenoids, like xanthophylls have gained nutritional significance due of their positive association in reduction of cardiovascular disease, cancer, obesity and age related degenerative diseases. Epidemiological and clinical trials have correlated the consumption of dietary carotenoids and decreased risk of major chronic and non-communicable diseases [1-3]. The xanthophylls consists diverse group of oxygenated carotenoids with varied structural properties. Among xanthophyll carotenoids, lutein, $\beta$-cryptoxanthin, capsanthin, astaxanthin, and fucoxanthin are evident as promising molecules. Lutein and itsisomer zeaxanthin are known as macular pigments and involved in protection of ocular health [4]. Astaxanthin is found in crustaceans, certain microalgae and mould, and demonstrated strongest antioxidant molecule than other carotenoids, vitamins and other phytochemicals. Likewise, fucoxanthin another major carotenoid pigment occurs in macro algae and seaweeds have attracted due to its anti-inflammatory and anti-cancer activity $[5,6]$. In addition, studies have also demonstrated that, effect of carotenoids may be due to its metabolites [7, 8]. Although, influence of oxygenated carotenoids in different animals and in vitro models [9] are available, however efficiency of each carotenoid with different functional group on a single cell model is not been well illustrated. Hence, this study aimed to screen the influence of oxygenated carotenoids such as, lutein (LUT, hydroxy-carotenoid) astaxanthin (AST, keto-carotenoid) and fucoxanthin (FUCO, epoxy-carotenoid) (Figure 1) on biochemical/molecular events of anti-inflammatory response in macrophages (RAW 264.7) and anti-proliferation effects in HL-60 cells.

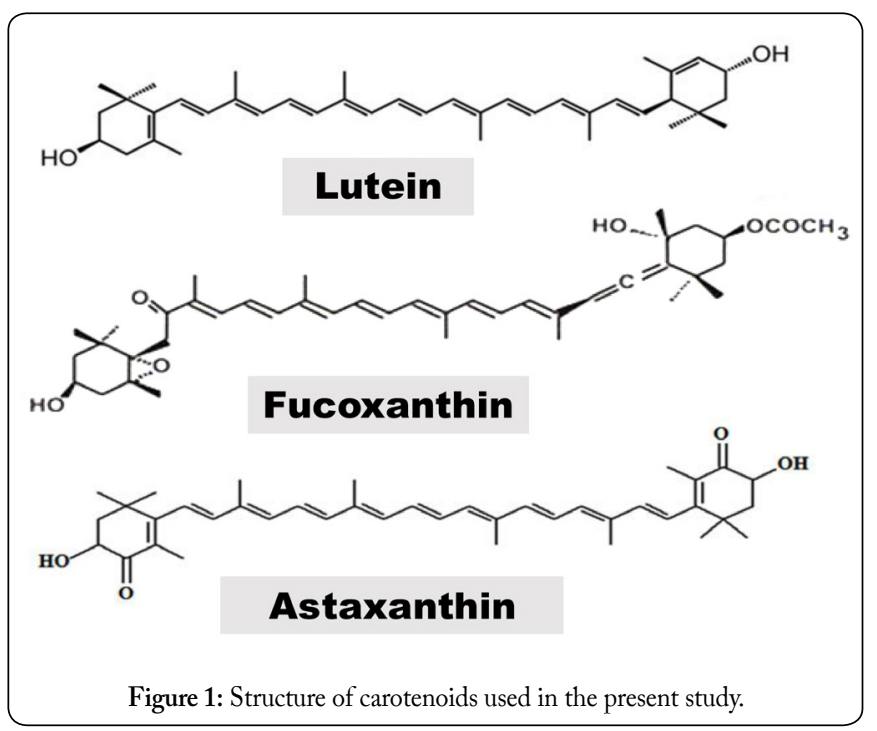

\section{Materials and Methods}

Standard LUT (99\%), AST (99\%), FUCO (98\%), Bovine serum albumin, Glutathione reductase (GR), Propidium iodide, Tetramethoxypropane (TMP), Sodium dodecyl sulfate (SDS), n-butanol, Poly-D-lysine, Ethidium bromide (EtBr), Acridine orange (AO), 4,6-diamidino-2-phenylindole, dilactate (DAPI) and cell culture grade dimethyl sulfoxide (DMSO) were purchased from Sigma-Aldrich (St. Louis, MO, USA). Dulbecco's modified eagle's medium (DMEM), Roswell Park Memorial Institute (RPMI) 1640 Medium, fetal bovine serum (FBS), 3-[4, 5-dimethylthiazol-2-yl]-2,5diphenyltetrazolium bromide (MTT), antibiotic-antimycotic solution, calcium and magnesium free phosphate buffer saline, trypan blue, cell culture consumables and neutral aluminium oxide (particle size: 70-230 mesh) were obtained from HiMedia Chemical Laboratories (Mumbai, India). All other chemicals and solvents of analytical and HPLC grades were purchased from Sisco Research Laboratories (Mumbai, India). FITC Annexin-V apoptosis detection kit was purchased from $\mathrm{BD}$ pharmingen (BD Bioscience, San Diego, CA). NF- $\kappa \mathrm{B}$ p-65, $\beta$-actin, goat anti-rabbit/mouse IgG-HRP secondary antibodies and western blotting luminol reagent were purchased from Santa Cruz Biotechnology (Santa Cruz, CA, USA). CLX-posureTM film (8 x 10 inches) and BCA assay reagent were procured from Thermo scientific.

\section{Extraction and purification of carotenoids}

LUT, a major di-hydroxy carotenoid from green leafy vegetables (spinach), keto-carotenoid, AST from shrimp (Penaeusmondon) samples (meat) and FUCO an epoxycarotenoid from brown seaweeds (Padina tetrasomatica) were isolated. LUT was isolated from spinach as per procedure established by our laboratory [10]. Likewise, AST and FUCO were isolated from the respective samples as per the established methods $[11,12]$ with slight modifications. In brief, shrimp meat portion $(100 \mathrm{~g})$ grounded using mixer grinder to obtain fine paste. A portion of homogenized sample $(10 \mathrm{~g})$ mixed and soaked in ice-cold acetone $(30 \mathrm{~mL})$ for 5 minutes and extracted carotenoid until residue became colourless. The pooled acetone extract filtered through Whatman No.1 paper, and the filtrate was subjected for mild saponification $(0.2 \%$ $\mathrm{NaOH})$ for $16 \mathrm{~h}$ in a ratio of $5: 1(\mathrm{v} / \mathrm{v})$. The saponified sample partitioned by adding an equal volume of $10 \%$ sodium sulfate and collected upper phase by repeated extraction. The pooled extract dried under $\mathrm{N}_{2}$ gas and dissolved in a known volume of acetone and subjected to purification on silica gel column. Similarly, FUCO extracted with acetone/methanol (7:3, $\mathrm{v} / \mathrm{v})$ repeatedly till the sample become colourless. The crude extracts evaporated and re-dissolved in methanol/hexane/ water $(1: 1: 0.2, \mathrm{v} / \mathrm{v} / \mathrm{v})$. The methanol/water phase separated and re-suspended in diethyl ether/water $(3: 4, v / v)$, swirled and collected upper diethyl ether phase and subjected further purification. All the process and preparations were done at $4{ }^{\circ} \mathrm{C}$ under dim yellow light to minimize photo-oxidation of carotenoids [10].

\section{Open column chromatography}

LUT rich fraction eluted by using $\mathrm{MeOH} / \mathrm{DCM}$ $(1: 1, \mathrm{v} / \mathrm{v})$ through column chromatography (OCC, $20 \mathrm{~cm} \times 1.5$ 
$\mathrm{cm})$ consists of neutral aluminium oxide $\left(\mathrm{Al}_{2} \mathrm{O}_{3}\right)$ (particle size: 70-230 mesh, SRL, Mumbai) [4]. AST separated on silica gel column (20 cm x $1.5 \mathrm{~cm}$, particle size: 60-120 mesh, SRL, Mumbai) using hexane-acetone (88:12, v/v) [11]. Likewise, FUCO rich fraction obtained using hexane/acetone $(6: 4, \mathrm{v} / \mathrm{v})$ on $\mathrm{Al}_{2} \mathrm{O}_{3}$ column [13].

\section{LC-MS (APCI) ${ }^{+}$analysis}

The purity of each isolated carotenoid was quantified from the HPLC peak area of respective standards. The analysis of carotenoids done by using RP-HPLC system consisting of the photodiode array (PDA) detector (SPD-M20A, Prominence, DAD) on C30 column ( $5 \mu \mathrm{m} ; 250 \times 4.6 \mathrm{~mm}$; Princeton, Cranbury, USA). Acetonitrile/methanol/dichloromethane $(60: 20: 20, \mathrm{v} / \mathrm{v} / \mathrm{v})$ containing $0.1 \%$ of ammonium acetate was used as mobile phase. An isocratic condition was performed at a flow rate of $1 \mathrm{~mL} / \mathrm{min}$ and monitored at 450 (LUT), 480 (AST) and $445.5 \mathrm{~nm}$ (FUCO). The peak identities and $\lambda_{\max }$ of purified carotenoids were confirmed by their retention time, characteristic UV-Vis, and LC-MS (APCI) ${ }^{+}$mass spectra of reference standards recorded under similar condition. Further, the purified carotenoids used for the cell culture studies to substitute commercial or synthetic with high cost value [10].

\section{Culture and treatments of RAW 264.7 and HL-60 cells}

Cell lines were procured from NCCS (Pune, India). RAW 264.7 cells cultured as monolayer in DMEM and HL-60 cells cultured as a suspension in RPMI medium supplemented with $10 \%$ heat-inactivated fetal bovine serum, $100 \mathrm{U}$ penicillin and $100 \mu \mathrm{g} / \mathrm{mL}$ streptomycin. Cells maintained in a humidified atmosphere of $95 \%$ air and $5 \% \mathrm{CO}_{2}$ at $37{ }^{\circ} \mathrm{C}$. Cells regularly passaged (twice in a week) and between 4-20 passages considered for experiments. Exponentially growing HL-60 cells $(70-80 \%)$ seeded $\left(5 \times 10^{3}\right.$ cells/ well) in a 96-well plate supplemented with $200 \mu \mathrm{L}$ of culture medium and incubated for $24 \mathrm{~h}$. Followed, replenish with $200 \mu \mathrm{L}$ of serum-free media consists of $20 \mu \mathrm{M}$ carotenoid (LUT or AST or FUCO) or without carotenoid (control) incubated for $48 \mathrm{~h}$. Then, MTT assay performed as per the existing procedure [14]. Similarly, cell viability of LPS $(1 \mu \mathrm{g})$ stimulated RAW 264.7 cells cotreated with or without $20 \mu \mathrm{M}$ carotenoid for $12 \mathrm{~h}[15,16]$.

Further, RAW 264.7 and HL-60 cells ( $2 \times 104 /$ well) seeded separately in 24 -well plates $(n=4)$ and incubated with or without $20 \mu \mathrm{M}$ carotenoid (LUT or AST or FUCO) delivered through DMSO or DMSO vehicle alone for 12 and $48 \mathrm{~h}$, respectively. Cells harvested and quadruplicate hemocytometer counts were performed. Trypan blue dye exclusion method used to evaluate the percentage of viable and dead cells. The viability of cells treated DMSO alone (control) considered as $100 \%$. Carotenoids samples prepared freshly in a nitrogen environment in a known volume of DMSO. The vehicle solvent system withdrawn from sealed ampoule by a syringe and purged nitrogen to prevent oxidation. Carotenoids stored at $-80{ }^{\circ} \mathrm{C}$ between each experiment to minimize oxidation decay.

\section{Lactate dehydrogenase (LDH) assay}

LDH release in LPS-stimulated RAW 264.7 cells cotreated with or without carotenoid for $12 \mathrm{~h}$ quantitated by using commercial LDH assay kit according to manufacturer's instructions (Lab-care diagnostics Pvt. Ltd. India). Determination of cytotoxicity in experimental samples measured as \% LDH release compared with control cells (without LPS treatment). Cells treated with 1\% Triton X-100 for same time point served as a positive control of the test system. A value of $>5 \% \mathrm{LDH}$ released into the culture media was considered as cytotoxic.

\section{Nitric oxide (NO) scavenging assay}

NO scavenging activity of the different carotenoids done as per the established procedure with slight modification [17]. In brief, RAW 264.7 cells $\left(10^{6}\right.$ cells $\left./ \mathrm{mL}\right)$ seeded on a 24 -well tissue culture plates and pre-incubated at $37^{\circ} \mathrm{C}$ for $12 \mathrm{~h}$ to achieve stable attachment. Further, LPS stimulated cells cotreated with or without carotenoid for $12 \mathrm{~h}$ and monitored $\mathrm{NO}$ production by measuring nitrite levels in the culture media using Griess Reagent at $540 \mathrm{~nm}$.

\section{Determination of $\mathrm{PGE}_{2}$ levels}

RAW 264.7 cells $\left(10^{6}\right.$ cells/ $\mathrm{mL}$ ) incubated with LPS and carotenoids for $12 \mathrm{~h}$. The level of $\mathrm{PGE}_{2}$ in the supernatants of cultured macrophage cell lysate was determined using a competitive enzyme immunoassay kit (Thermo Fisher Scientific, India) according to the manufacturer's protocol. Celecoxib $(3 \mu \mathrm{M})$ was used as a positive control. The levels of $\mathrm{PGE}_{2}$ in cells were established according to the regression equation of the standard curve [18].

\section{Western blot analysis of NF-KB p65}

RAW 264.7 cells seeded in $100 \mathrm{~mm}$ dish $\left(10 \times 10^{6}\right)$ and cultured overnight. Then, cells stimulated with LPS (1 $\mu \mathrm{g} /$ $\mathrm{mL}$ ), and co-treated either with LUT or AST or FUCO or no carotenoid for $12 \mathrm{~h}$. After incubation, cells rinsed in ice-cold PBS twice and harvested by scraping. Cytoplasmic and nuclear proteins separated by using NE-PER Nuclear and cytoplasmic extraction kit (Thermo Fisher Scientific, India). The BCA assay was done to estimate total protein content. In each sample, $30 \mu \mathrm{g}$ of protein loaded per lane for separation in $10 \%$ polyacrylamide gel and then transferred electrophoretically on to nitrocellulose membrane. After blocking for $1 \mathrm{~h}$ with blocking buffer, the membranes were incubated overnight at $4{ }^{\circ} \mathrm{C}$ with antibodies against $\beta$-actin (loading control) or NF- $\kappa \mathrm{B}$ p65.The primary antibodies detected by using HRP labelled goat anti-rabbit/mouse immunoglobulin $G$ secondary antibodies. A chemiluminescence kit (Santa Cruz Biotechnology, Santa Cruz, CA) used to visualize protein bands. In each experiment, three X-ray film exposures (10 to $15 \mathrm{~min}$ ) of the blot scanned and calculated the levels of proteins expression by densitometry analysis [19].

\section{Measurement of glutathione and malondialdehyde (MDA)} levels in HL-60 cells

Cell lysate of HL-60 cells treated with or without carotenoids for $48 \mathrm{~h}$ was prepared and analyzed glutathione [20] and MDA levels [21]. The processing of cell pellet, cell lysate, and other reagent preparation were done as per Sowmya et al. [14]. Protein estimation was done according to Lowry et al. [22]. 


\section{Apoptosis detection by Annexin FITC and PI staining}

Apoptosis detection performed with FITC Annexin V apoptosis detection kit (BD pharmingen, BD Bioscience, San Diego, CA) according to manufacturer's instructions. Briefly, after incubation LPS-stimulated RAW 264.7 (12 h) and HL60 cells $(48 \mathrm{~h})$ with and without carotenoids harvested and washed with the ice-cold PBS and centrifuged at $3000 \mathrm{rpm}$ for $5 \mathrm{~min}$ at $4{ }^{\circ} \mathrm{C}$. The cells grown as a monolayer included both harvested by trypsinization and floating in the medium. The cell pellet was re-suspended in an ice-cold binding buffer, followed by FITC Annexin V $(1 \mu \mathrm{L} / \mathrm{mL})$ and PI $(10 \mu \mathrm{L} / \mathrm{mL})$ solutions were added. Sample tubes incubated for $15 \mathrm{~min}$ in a dark at room temperature before flow cytometry analyses [14].

\section{Measurement of reactive oxygen species (ROS)}

LPS-stimulated RAW 264.7 and HL-60 cells $\left(1 \times 10^{6}\right)$ treated either with or without LUT, AST and FUCO were harvested and were co-activated with 2'-7'-dichlorofluoresceindiacetate (DCF) for $30 \mathrm{~min}$. DCF intensity was measured using the fluorescence spectrophotometer (excitation $484 \mathrm{~nm} /$ emission $531 \mathrm{~nm}$ ) [23]

\section{Morphological evaluation by $\mathrm{AO} / \mathrm{EtBr}$ staining}

The effects of LUT, AST and FUCO on LPS-stimulated RAW 264.7 and HL-60 cells were determined by dual staining with Acridine orange and ethidium bromide (AO/ EtBr). Cells were seeded on poly- L-lysine (0.01\%) coated cover slip and kept in the $\mathrm{CO}_{2}$ incubator for $24 \mathrm{~h}$, then LUT, AST and FUCO were treated separately and incubated for $48 \mathrm{~h}$ and $12 \mathrm{~h}$ for HL-60 and RAW 264.7 cells, respectively. After incubation, the cells were washed twice with PBS, followed by stained with $10 \mu \mathrm{L}$ of dye mixture $(100 \mu \mathrm{g} / \mathrm{mL}$ of $\mathrm{AO}$ and $100 \mu \mathrm{g} / \mathrm{mL}$ of EtBr) in PBS for 2-3 min. The effect of individual carotenoid or their combination on cellular and morphological changes were documented by fluorescence microscope with excitation/emission filters $(360 / 590 \mathrm{~nm}$ for $\mathrm{EtBr}$ and $480 / 510 \mathrm{~nm}$ for $\mathrm{AO}$ ) with the exposure time 5500 milliseconds under 200x magnification [24].

\section{Statistical analysis}

Values are mean \pm SEM of five samples. Data tested for homogeneity of variances by the Bartlett test. When homogenous variances confirmed, the data were further analyzed by using ANOVA (Assistant software, v.7.7). The differences between carotenoids, LPS and vehicle controls group were analyzed by Tukey's test. The differences between the experimental samples were considered significant levels at $\mathrm{p}<0.05$.

\section{Results}

\section{Carotenoids content and purity from natural source}

Carotenoids isolated from spinach, shrimp and seaweeds were identified and confirmed based on their $\lambda_{\max }$, retention time, characteristic UV-Visible, and mass spectra. Mass spectra of LUT, AST and FUCO were compared with their respective reference standard and were used for cell culture treatments. The purity of column purified LUT, AST and FUCO were $97 \pm 1,96 \pm 3$, and $94 \pm 2 \%$, respectively. The results show that the levels of LUT in spinach were $78 \pm 2$ $\mu \mathrm{g} / \mathrm{g}$ dry weights, while AST in shrimp was $50 \pm 2 \mu \mathrm{g} / \mathrm{g}$ dry weights, respectively. Padina tetrasomatica consists of $42.8 \pm 5$ $\mu \mathrm{g} / \mathrm{g}$ dry weights FUCO as the major pigment, respectively. Cell viability/toxicity levels between purified carotenoids and respective standards were comparable, and there is no significant difference in treated cultures.

\section{Effect of LUT, AST and FUCO on RAW 264.7 cell viability} and LDH assay

The cytotoxicity influence of the carotenoids treatments in LPS-stimulated RAW 264.7 cells is shown in Figure 2A. The LPS-stimulated cells decreased cell viability by $85 \%$. Whereas, LUT, AST and FUCO delivered separately in DMSO increased cell viability by, 58.3, 63.4 and $74.1 \%$ as compared to LPS-stimulated, respectively. Also observed in the LDH assay,
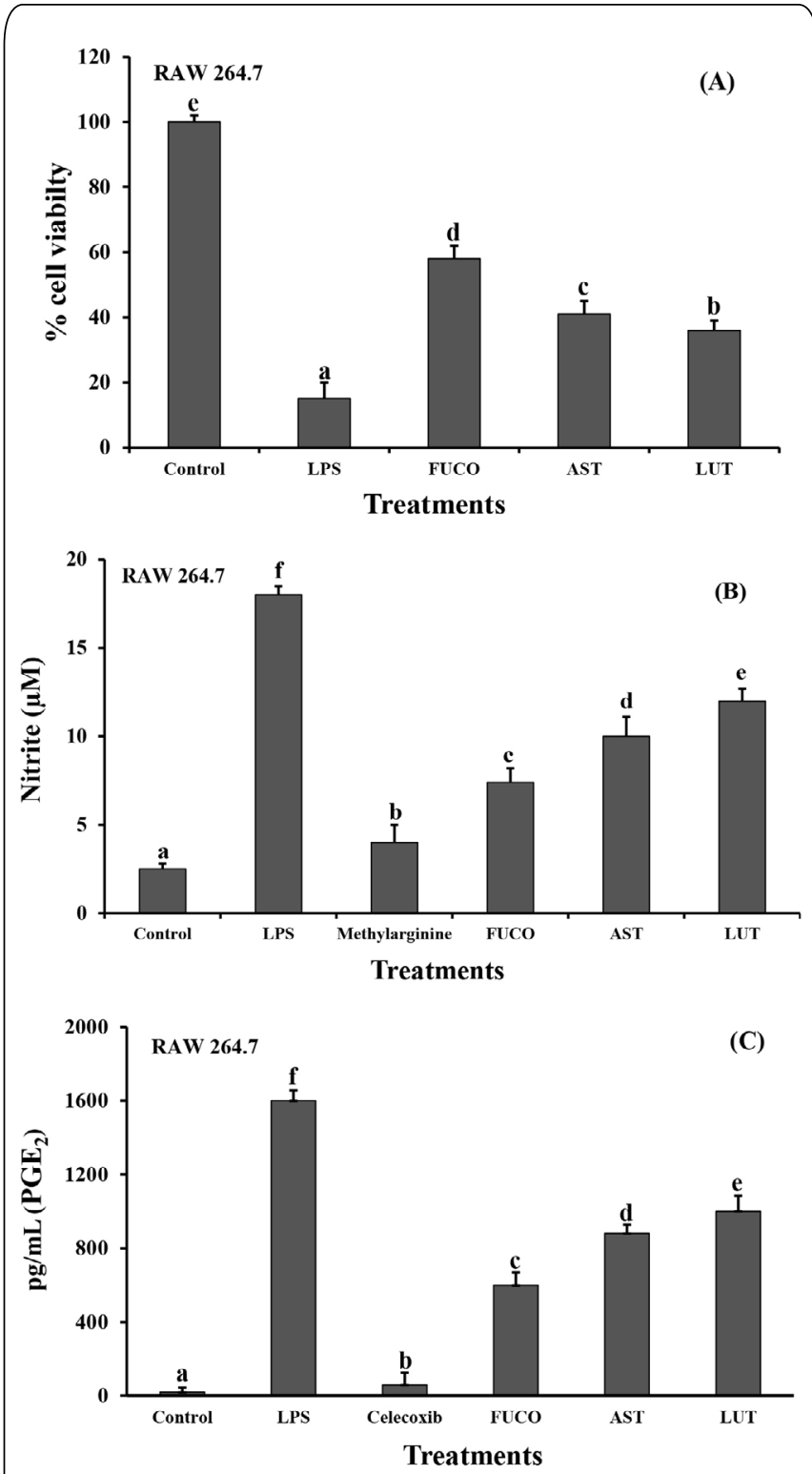

Figure 2: Effect of purified carotenoids (FUCO/AST/LUT) $(20 \mu \mathrm{M})$ from seaweeds on LPS-induced cell viability (A), NO production (B) and $\mathrm{PGE}_{2}$ production (C) in RAW 264.7 cells for 12 h. a,b,c,d,e,f Values were the means \pm SEM of three different experiments. Values with different letters were significantly different $(\mathrm{p}<0.05)$. 
a clear increase of $\% \mathrm{LDH}$ in the culture medium was found in LPS treated group. The lowest \% LDH release was observed in FUCO (8\%) treated followed by AST (12\%) and LUT (18\%). These results indicate that FUCO treated group increased cell viability significantly compared to other groups by protecting cells from LPS-stimulated inflammation.

Effect of LUT, AST and FUCO in nitric oxide scavenging and $\mathrm{PGE}_{2}$ production in RAW 264.7 cells

Carotenoids used in the present study effectively suppress the LPS-stimulated NO production (Figure 2B). LUT, AST, and FUCO decreased NO by 33.3, 44.4 and 58.8\% as compared to LPS-stimulated cells, respectively. Similarly, $\mathrm{PGE}_{2}$ production increased in the culture medium treated with LPS. Whereas, LUT, AST and FUCO significantly inhibited PGE levels by $37.5,45$ and $62.5 \%$ as compared to LPS-stimulated cells in RAW 264.7 cells, respectively (Figure $2 \mathrm{~B}$ and $2 \mathrm{C}$ ).

\section{Effect of LUT, AST and FUCO on NF-KB p65 level}

In order to understand the mechanism underlying the inhibitory effect of the LUT, AST and FUCO on LPSstimulated inflammatory mediators, we studied the NF- $\kappa B$ p65 level in the nuclear fraction of the treated cells by western blotting. The amount of NF- $\kappa \mathrm{B}$ p65 in the nucleus of RAW 264.7 dramatically increased upon stimulation with LPS. Carotenoids treatment reduced the expression of nuclear NF$\kappa \mathrm{B}$ p65, whereas FUCO shown a more evident inhibition. All the three carotenoids exerted their anti-inflammatory actions by down-regulating of NF- $\kappa \mathrm{B}$ p65 level in macrophage cells. The fold difference was found to be 2.1, 3.3 and 6.8 in LUT, AST and FUCO as compared to LPS-stimulated group, respectively (Figure 3).

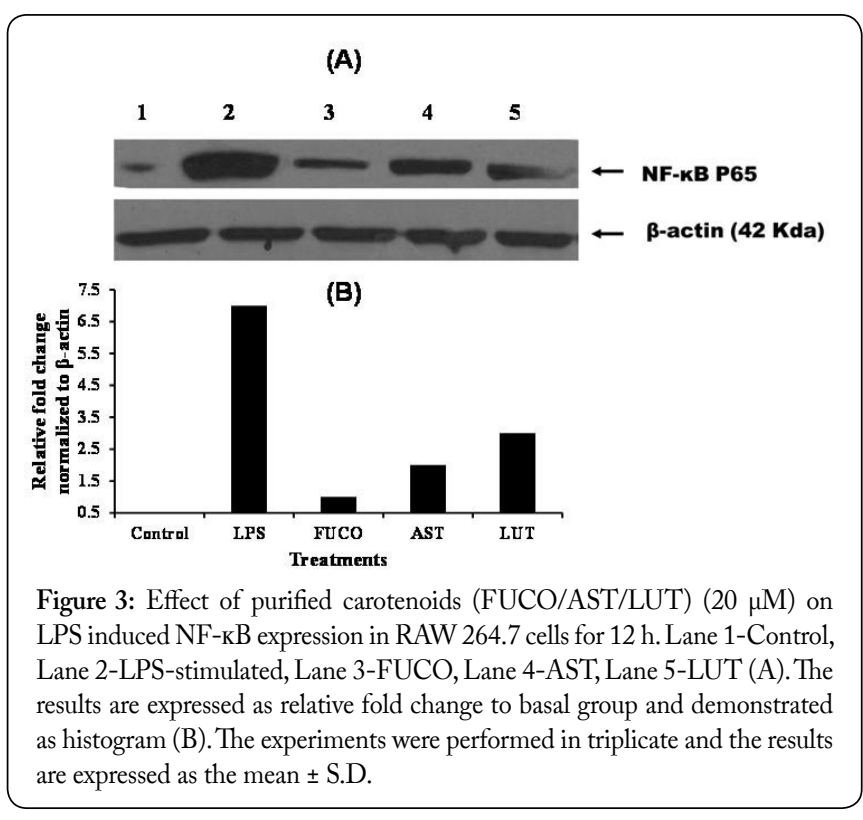

Cell viability and oxidative status of $\mathrm{HL}-60$ cells treated with LUT, AST and FUCO

Carotenoids drastically decreased cell viability after $48 \mathrm{~h}$ of incubation (Figure 4A). LUT, AST and FUCO reduced cell viability by 22,39 and $55.4 \%$ in HL-60 cells, respectively. Also,
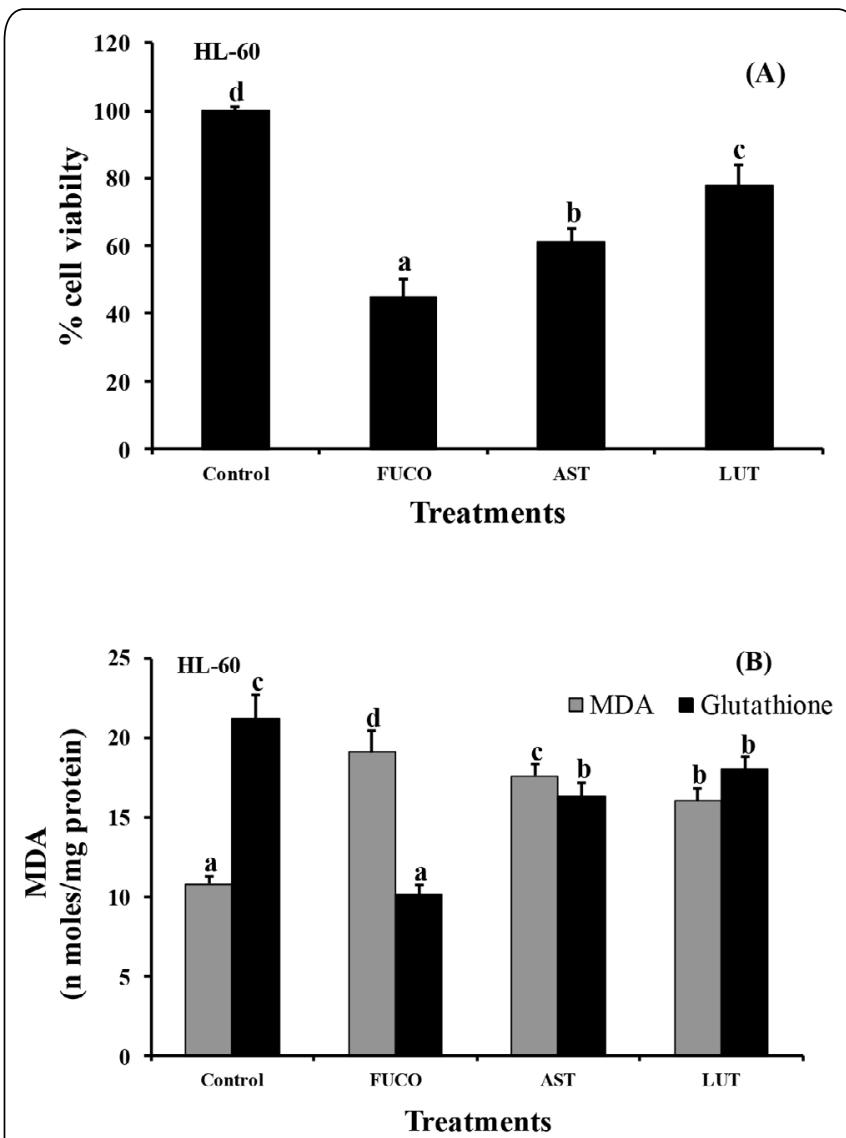

Figure 4: Effect of purified carotenoids $(20 \mu \mathrm{M})$ treatments $(48 \mathrm{~h})$ on cell viability (A), glutathione and MDA levels in HL-60 cells (B) ${ }^{\mathrm{a}, \mathrm{b}, \mathrm{c}, \mathrm{d}}$ Values were the means \pm SEM of three different experiments. Values sharing different letters are significantly different $(\mathrm{p}<0.05)$.

FUCO decreased glutathione (37.3 and 18\%) and increased MDA levels (55.8 and 71.1\%) significantly in HL-60 cells as compared to LUT and AST treated groups (Figure 4B).

Effect of LUT, AST and FUCO on induction of apoptosis and ROS generation in RAW 264.7 and HL-60 cells

Induction of apoptosis was confirmed by using FITC Annexin V and PI staining. The relative \% of apoptotic cells and ROS generation in carotenoids treatment groups is shown in Table 1 . The \% apoptosis in RAW 264.7 cells decreased in LUT (26.6\%), AST (34.7\%), and FUCO (41.8\%) than LPS treated group. Likewise, decreased levels of ROS generation observed in LUT (22.1\%), AST (25.4\%), and FUCO (36.5\%) than LPS treated group.

In case of HL-60 cells, the \% apoptotic cells higher in LUT (5\%), AST (11.5\%) and FUCO (18.1\%) than control treatment. In addition, FUCO shown slightly higher levels of ROS generation than LUT (4.7\%) and AST (8.6\%) treated group.

Effect of LUT, AST and FUCO on HL-60 and RAW 264.7 cells morphology

Morphological changes in cells were confirmed by acridine orange and ethidium bromide staining $(\mathrm{AO} / \mathrm{EtBr}$ staining) in cells treated with LUT, AST and FUCO. Cells stained with fluorescence green, yellow and reddish /orange represented viability, early apoptosis, and late apoptosis, respectively 
(Figure 5). HL-60 cells treated with carotenoids showed changes in cellular morphology, FUCO being more effective compared to AST and LUT and similar trend was observed as in case of cell viability assay. Whereas, LPS-stimulated RAW 264.7 cells induces apoptotic/necrosis, upon treatment with carotenoids cells retained towards normal morphology in the following order FUCO >AST $>$ LUT.

Table 1: Effect of carotenoids on induction of apoptosis and ROS levels in HL-60 and RAW 264.7 cells.

\begin{tabular}{|c|c|c|}
\hline $\begin{array}{c}\text { Experimental } \\
\text { groups }\end{array}$ & Apoptosis (\%) & ROS (\%) \\
\hline CN & \multicolumn{2}{|c|}{ HL-60 } \\
\hline FUCO $^{*}$ & $20.30 \pm 0.6^{\mathrm{d}}$ & $17.3 \pm 0.6^{\mathrm{a}}$ \\
\hline LUT $^{*}$ & $7.2 \pm 1.7^{\mathrm{b}}$ & $6.5 \pm 0.9^{\mathrm{b}}$ \\
\hline AST $^{*}$ & $13.7 \pm 0.8^{\mathrm{c}}$ & $10.4 \pm 0.4^{\mathrm{c}}$ \\
\hline CN $^{|c|}$ RAW 264.7 \\
\hline LPS $^{\mathrm{d}}$ & $3.22 \pm 1.6^{\mathrm{a}}$ & $4.62 \pm 0.6^{\mathrm{a}}$ \\
\hline FUCO $^{*}$ & $70.3 \pm 2.7^{\mathrm{e}}$ & $63.8 \pm 1.3^{\mathrm{e}}$ \\
\hline LUT $^{*}$ & $28.5 \pm 0.7^{\mathrm{b}}$ & $27.3 \pm 0.9^{\mathrm{b}}$ \\
\hline AST $^{*}$ & $43.7 \pm 1.2^{\mathrm{d}}$ & $41.7 \pm 1.5^{\mathrm{d}}$ \\
\hline
\end{tabular}

*20 $\mu \mathrm{M}$ of individual carotenoid of OCC purified LUT from GLVs, AST from shrimp and FUCO from seaweed. The values are means \pm of SEM of three experiments. Values not sharing a common superscript letter within a column under each treatment are significantly different from its respective control at $p<0.05$.

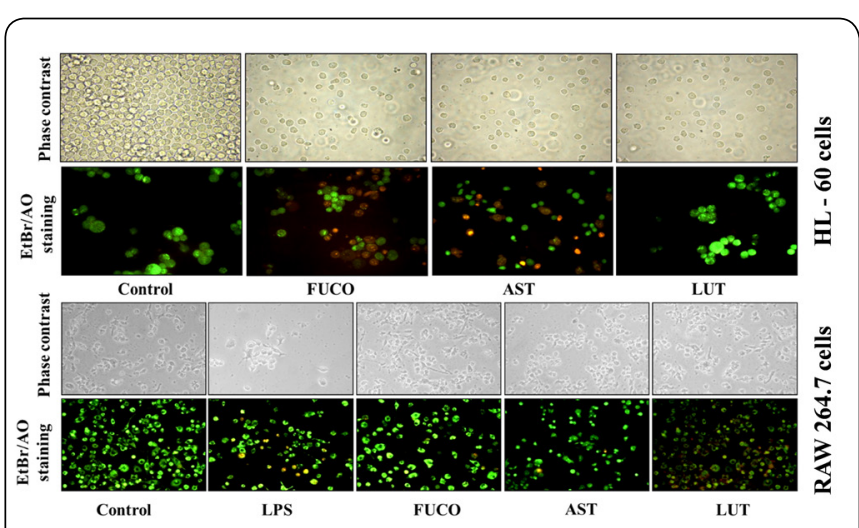

Figure 5: Effect of carotenoids ( $20 \mu \mathrm{M}$ of LUT/AST/ FUCO) on HL-60 and RAW 264.7 cell morphology incubated for 48 and $12 \mathrm{~h}$, respectively. Cells were stained with and without $\mathrm{AO} / \mathrm{EtBr}$ and observed under phase contrast and fluorescence microscope (200x). Green live cells show normal morphology; green early apoptotic cells show nuclear margination and chromatin condensation. Late orange apoptotic cells showed fragmented chromatin and apoptotic bodies. These are representative results of at least three independent experiments $(n=3)$.

\section{Discussion}

Carotenoids role in several degenerative diseases have been focused from past two decades, however effect of specific xanthophyll are less focused. Although, carotenoids are linked to anti-inflammation, oxidative stress and antiproliferation of cancer cells, perhaps many aspects are poorly understood. Therefore, in the present study, the potentiality of three selected oxygenated carotenoids on inflammation and cancer cell proliferation were evaluated. Several scientific reports demonstrated the carotenoids influence on markers of oxidative stress and inflammation indicating positive health benefits, by persuading transcription factors, and their downstream targets [25-29]. NO have been shown to cause DNA damage that can ultimately leads to development of chronic diseases and cancer [30]. Macrophages play an important role in both, host-defense mechanisms and inflammation. Activated macrophages secrete a number of different inflammatory mediators, including NO, TNF- $\alpha$, IL$1 \beta$ and IL-6. The overproduction of these mediators has been implicated in several inflammatory diseases and cancer [31]. Thus, inhibition of activation of these cells appears to be an important target for the treatment of inflammatory diseases. $\mathrm{NO}$ is one ubiquitous cellular mediator of physiological and pathological processes, being largely released at inflammatory sites [32]. In this study, it is evident that epoxy-carotenoid like FUCO exerted higher anti-inflammatory property in RAW 264.7 and demonstrated its superior role in controlling HL-60 cell proliferation. Leukemia cells considered as a bipotent cell line with the capacity to differentiate into granulocytes and macrophages/monocytes [33], hence, we tested our hypothesis using RAW 264.7 and HL-60 cell lines.

In the current study, we observed that oxygenated carotenoids shown to control inflammation effectively in RAW 264.7 cells, further each kind of carotenoid at similar concentration inhibits production of $\mathrm{NO}, \mathrm{PGE}_{2}$ and $\mathrm{ROS}$ with different potencies. Anti-proliferation activity of each oxygenated carotenoid on higher percentages of apoptotic/ necrotic cells may be due to inflammation triggered by LPS. Whereas, cells co-treated with carotenoids for $12 \mathrm{~h}$ decreased the induction of necrosis/ apoptosis and retains its proliferation. These results positively correlated with decreased production of ROS generation in carotenoid treated groups. Among these parameters, FUCO exhibited to shown better inhibition than hydroxy and keto-carotenoids. Further the key biomarker of inflammation, $\mathrm{NF}-\kappa \mathrm{B}$ p65 inhibits the expression by 3.5 and 4.7 folds in FUCO than AST and LUT. These results are well supported by earlier report with inhibition of NO production, prostaglandins, and related expression of inflammatory genes by suppressing the activation of transcription factor $\mathrm{NF}-\kappa \mathrm{B}$ p65 by hydrocarbon carotenoid $\beta$-carotene [34].

Violaxanthin is recently known to be potent antiinflammatory agents in vitro and in vivo in responses to bacterial LPS [18]. Shiratori et al. [35] reported that effect of FUCO is comparable with commercially anti-inflammatory steroidal drug prednisolone. Heo et al. [36] screened inhibitory effect of $\mathrm{NO}$ production from nine species of brown algae and confirmed that inhibition of $\mathrm{NO}$ production correlates with FUCO contents. FUCO treatment attenuates the productions of $\mathrm{NO}$ and $\mathrm{PGE}_{2}$ by inhibiting inducible $\mathrm{NO}$ synthase (iNOS) and cyclooxigenase-2 (COX-2) expressions. 
The anti-inflammatory activities of selected oxygenated carotenoids may be due to the suppression of $\mathrm{NF}-\kappa \mathrm{B}$ as similar to previous observation $[5,34]$. $N F-\kappa B$ plays a decisive role in the transcriptional regulation of a wide range of genes that are involved in regulation of inflammatory and immunity. $\mathrm{NF}-\kappa \mathrm{B}$ proteins exist in the cytoplasm of inactive cells, but upon stimulation they become active and translocate into the nucleus, inducing transcription of diverse inflammatory genes. In this study we found that FUCO from seaweed lowers the transactivation of $\mathrm{NF}-\kappa \mathrm{B}$ p65 in the nucleus more prominently as compared to hydroxy and keto-carotenoids treatments in LPS-stimulated macrophage cells. Production of pro-inflammatory mediators has been continuously reported in many inflammatory tissues, along with increased expression of their mRNAs and proteins. Therefore, inhibition of proinflammatory mediators by these carotenoids suggesting that its potentiality to treat the inflammatory and other related diseases.

This study also evaluated the anti-proliferative activity of FUCO, AST and LUT in HL-60 cells. Previously, carotenoids demonstrated the range of biological properties, including, antioxidant, cytotoxicity, modulation of gene expression and signalling [9]. In this study, FUCO affects significantly on anti-proliferation of HL-60 cells than hydroxy and ketocarotenoids at similar concentration. Earlier, Chew et al. [37] have reported antitumor effect of AST in mouse models. Others have also attributed the role of AST and other carotenoids against cancer in various cell lines $[38,39]$. Similarly, chemopreventive action of di-hydroxy carotenoid LUT has been recognized in tumour-induced female BALB/c mice [2]. In the present study, we shown the effect of structurally different oxygenated carotenoids on cytotoxicity in HL-60 cells. Further, we also observed that, FUCO treated cells significantly affects induction of apoptosis followed by AST, and LUT. This difference may be due to structurally different carotenoids having variable polarity and solubility in the medium [40]. Apart from these, uptake of carotenoid and its level in cells may also be accountable in the biochemical events of cell toxicity $[7,41,42]$. The different sensitivities of the cells to carotenoids are presumably due to the difference in absorption of carotenoids [43]. It is possible that cell growth modality, as well as cell metabolic status and membrane composition, may influence carotenoid accumulation. Oxidative stress plays important role in the induction of apoptosis in diverse models [44]. We believe that reduced glutathione and increased MDA levels may induce apoptosis. Since glutathione serves as an endogenous antioxidant, reduced glutathione levels reported to facilitating apoptosis in leukemic cancer cells [45] FUCO was found to perform superior bioactive molecule and inhibits greatly on proliferation of cancer cells than AST, and LUT. Hence, FUCO induces higher cytotoxicity and percent apoptosis of HL-60 cells due to increase oxidative stress in cancer cells as indicated by the higher accumulation of MDA and depleted levels of glutathione [8]. Further, support to this observation, FUCO treated group showed higher ROS level followed by AST, LUT and control (Figure 4 and Table 1). Earlier, studies have demonstrated that epoxy xanthophylls such as fucoxanthin and neoxanthin reduce the viability of prostate cancer cells by inducing apoptosis to a greater extent than the lutein, $\beta$-carotene and lycopene [46]. In addition, Palozza et al. [42] demonstrated that under the experimental condition, carotenoids acts as pro-oxidants predominate over the antioxidant and induce the formation of free radical species, including peroxyl radicals, and responsible for an induction of apoptosis. In this study, oxygenated carotenoids inhibited HL-60 cells proliferation by accumulation of ROS. This difference among oxygenated carotenoid may be due to functional group and reactivity of carotenoids or its breakdown products with cancer cells. Previously, it has been suggested that an increase in the number of oxygen or hydroxyl groups in the carotenoids decides the efficiency of antioxidant activity [47]. Apoptosis detection by Annexin/FITC staining confirmed the anti-proliferative effect of oxygenated carotenoids. The higher apoptosis of cells may be due to the increased oxidative stress in cells treated with FUCO followed by AST and LUT. Carotenoids may act as antioxidants or as pro-oxidants in biological systems, depending on their concentration and oxygen tension [7,48]. Also, the observation of apoptotic morphological features in carotenoids treated group strongly suggested the influence of oxygenated carotenoids in cancer cell proliferation. Further, apoptosis process may be due to, at least in part, to the formation of its oxidative breakdown products, while reported to render higher toxicity to cancer cells $[7,8]$.

\section{Conclusion}

This study demonstrated the variable potentiality of individual oxygenated carotenoid related to anti-inflammation and anti-proliferation activities, the difference presumed may due to its chemical and structural properties. Interaction of bioactive FUCO with hydrocarbon carotenoids and other phyto-components from intra specific food/natural source is deserved for further exploration of characteristics carotenoid. This observation provides a greater insight of oxygenated carotenoids consumption from green vegetables and marine food sources to combat chemoprevention of cancers originating from inflammation.

\section{Conflict of Interest}

The authors declare no competing financial interest.

\section{Acknowledgments}

Authors acknowledge the Department of Science \& Technology, Government of India, for the grant (NO. SB/EMEQ-233/2013) \& Department of Biotechnology, Bangalore University, UGC-SAP, \& DST-FIST facilities. Authors also acknowledge Prof. Raghavan Varadarajan (Chairman, Molecular Biophysics Unit, Indian Institute of Science, Bengaluru-560012) for the flow-cytometer facility and Dr. Harsha Gowda (Scientist, Institute of Bioinformatics, Bengaluru) for providing primary and secondary antibodies and molecular biology facility.

\section{References}

1. Bone RA, Landrum JT, Guerra LH, Ruiz CA. 2003. Lutein and 
zeaxanthin dietary supplements raise macular pigment density and serum concentrations of these carotenoids in humans. J Nutr 133(4): 992-998.

2. Chew BP, Brown CM, Park JS, Mixter PF. 2003. Dietary lutein inhibits mouse mammary tumor growth by regulating angiogenesis and apoptosis. Anticancer Res 23(4): 3333-3339.

3. Boeing H, Bechthold A, Bub A, Ellinger S, Haller D, et al. 2012. Critical review: vegetables and fruit in the prevention of chronic diseases. Eur J Nutr 51(6): 637-663. doi: 10.1007/s00394-012-0380-y

4. Lakshminarayana R, Aruna G, Sangeetha RK, Bhaskar N, Divakar S, et al.2008. Possible degradation/biotransformation of lutein in vitro and in vivo: isolation and structural elucidation of lutein metabolites by HPLC and LC-MS (atmospheric pressure chemical ionization). Free Radic Biol Med 45(7): 982-993. doi: 10.1016/j.freeradbiomed.2008.06.011

5. Kim KN, Heo SJ, Yoon WJ, Kang SM, Ahn G, et al. 2010. Fucoxanthin inhibits the inflammatory response by suppressing the activation of $\mathrm{NF}-\kappa \mathrm{B}$ and MAPKs in lipopolysaccharide-induced RAW 264.7 macrophages. Eur J Pharm 649(1-3): 369-375. doi: 10.1016/j. ejphar.2010.09.032

6. Woo MN, Jeon SM, Kim HJ, Lee MK, Shin SK, et al.2010. Fucoxanthin supplementation improves plasma and hepatic lipid metabolism and blood glucose concentration in high-fat fed C57BL/6N mice. Chem Biol Interact 186(3): 316-322. doi: 10.1016/j.cbi.2010.05.006

7. Palozza P, Serini S, Di Nicuolo F, Calviello G. 2004. Modulation of apoptotic signalling by carotenoids in cancer cells. Arch Biochem Biophys 430(1): 104-109. doi: 10.1016/j.abb.2004.02.038

8. Lakshminarayana R,Aruna G, Sathish V, Shylaja MD, Baskaran V.2013. Structural elucidation of possible lutein oxidation products mediated through peroxyl radical inducer 2, 2'-Azobis (2 methylpropionamidine) dihydrochloride: antioxidant and cytotoxic influence of oxidized lutein in HeLa cells. Chem Biol Interact 203(2): 448-455. doi: 10.1016/j. cbi.2013.03.006

9. Hussein G, Sankawa U, Goto H, Matsumoto K, Watanabe H. 2006. Astaxanthin, a carotenoid with potential in human health and nutrition. J Nat Prod 69(3): 443-449. doi: 10.1021/np050354+

10. Lakshminarayana R, Raju M, Krishnakantha TP, Baskaran V. 2005. Determination of major carotenoids in few Indian leafy vegetables by high-performance liquid chromatography. J Agric Food Chem 53(8): 2838-2842. doi: 10.1021/jf0481711

11. Lin WC, Chien JT, Chen BH. 2005. Determination of carotenoids in spear shrimp shells (Parapenaeopsis hardwickii) by liquid chromatography. J Agric Food Chem 53(13): 5144-5149. doi: 10.1021/jf050664y

12. Sangeetha RK, Bhaskar N, Baskaran V. 2009. Comparative effects of beta-carotene and fucoxanthin on retinol deficiency induced oxidative stress in rats. Mol Cell Biochem 331(1-2): 59-67. doi: 10.1007/s11010009-0145-y

13. Sangeetha RK, Bhaskar N, Divakar S, Baskaran V. 2010. Bioavailability and metabolism of fucoxanthin in rats: structural characterization of metabolites by LC-MS (APCI). Mol Cell Biochem 333(1-2): 299-310. doi: 10.1007/s11010-009-0231-1

14. Sowmya PR, Arathi BP, Vijay K, Baskaran V, Lakshminarayana R. 2015. Role of different vehicles in carotenoids delivery and their influence on cell viability, cell cycle progression, and induction of apoptosis in HeLa cells. Mol Cell Biochem 406(1-2): 245-253. doi: 10.1007/s11010-0152442-y

15. Kotake-Nara E, Kushiro M, Zhang H, Sugawara T, Miyashita K, et al. 2001. Carotenoids affect proliferation of human prostate cancer cells. $J$ Nutr 131(12): 3303-3306.

16. Takahashi K, Hosokawa M, Kasajima H, Hatanaka K, Kudo K, et al. 2015. Anticancer effects of fucoxanthin and fucoxanthinol on colorectal cancer cell lines and colorectal cancer tissues. Oncol Lett 10(3): 14631467. doi: $10.3892 /$ ol.2015.3380

17. Islam MN, Ishita IJ, Jin SE, Choi RJ, Lee CM, et al. 2013. Antiinflammatory activity of edible brown alga Saccharina japonica and its constituents pheophorbide a and pheophytin a in LPS-stimulated RAW 264.7 macrophage cells. Food Chem Toxicol 55: 541-548. doi: 10.1016/j.fct.2013.01.054

18. Soontornchaiboon W, Joo SS, Kim SM. 2012. Anti-inflammatory effects of violaxanthin isolated from microalga Chlorella ellipsoidea in RAW 264.7 macrophages. Biol Pharm Bull 35(7): 1137-1144. doi: 10.1248/bpb.b12-00187

19. Lee SJ, Bai SK, Lee KS, Namkoong S, Na HJ, et al. 2003. Astaxanthin inhibits nitric oxide production and inflammatory gene expression by suppressing I(kappa)B kinase-dependent NF-kappaB activation. Mol Cells 16(1): 97-105.

20. Tietze F. 1969. Enzymatic method for quantitative determination of nano gram amounts of total and oxidized glutathione: applications to mammalian blood and other tissues. Anal Biochem 27(3): 502-522. doi: 10.1016/0003-2697(69)90064-5

21. Ohkawa H, Ohishi N, Yagi K. 1979. Assay for lipid peroxides in animal tissues by thiobarbituric acid reaction. Anal Biochem 95(2): 351-358. doi: 10.1016/0003-2697(79)90738-3

22. Lowry OH, Rosebrough NJ, Farr AL, Randall RJ. 1951. Protein estimation with Folin phenol reagent. J Biol Chem 193(1): 265-275.

23. Song XD, Zhang JJ, Wang MR, Liu WB, Gu XB, et al. 2011. Astaxanthin induces mitochondria-mediated apoptosis in rat hepatocellular carcinoma CBRH-7919 cells. Biol Pharm Bull 34(6): 839-844. doi: 10.1248/bpb.34.839

24. Cury-Boaventura MF, Pompeia C, Curi R. 2004. Comparative toxicity of oleic acid and linoleic acid on Jurkat cells. Clin Nutr 23(4): 721-732. doi: 10.1016/j.clnu.2003.12.004

25. Marin DP, Bolin AP, Macedo RC, Sampaio SC, Otton R. 2011. ROS production in neutrophils from alloxan-induced diabetic rats treated in vivo with astaxanthin. Int Immunopharmacol 11(1): 103-109. doi: 10.1016/j.intimp.2010.10.013

26. Mannisto S, Smith-Warner SA, Spiegelman D, Albanes D, Anderson $\mathrm{K}$, et al. 2004. Dietary carotenoids and risk of lung cancer in a pooled analysis of seven cohort studies. Cancer Epidemiol Biomarkers Prev 13(1): 40-48. doi: 10.1158/1055-9965.EPI-038-3

27. Osganian SK, Stampfer MJ, Rimm E, Spiegelman D, Manson JE. 2003. Dietary carotenoids and risk of coronary artery disease in women. Am J Clin Nutr 77(6): 1390-1399.

28. Ritchlin CT, Haas-Smith SA, Li P, Hicks DG, Schwarz EM. 2003. Mechanism of TNF-alpha- and RANKL mediated osteoclastogenesis and bone resorption in psoriatic arthritis. J Clin Invest 111(6): 821-831. doi: 10.1172/JCI200316069

29. Guslandi M. 1998. Nitric oxide and inflammatory bowel disease. Eur J Clin Invest 28(11): 904-907. doi: 10.1046/j.1365-2362.1998.00377.x

30. Wink DA, Kasprzak KS, Maragos CM, Elespuru, RK, Misra M, et al. 1991. DNA deaminating ability and genotoxicity of nitric oxide and its progenitors. Science 254(5034): 1001-1003. doi: 10.1126/ science. 1948068

31. Lin WW, Karin M. 2007. A cytokine-mediated link between innate immunity, inflammation, and cancer. J Clin Invest 117(5): 1175-1183. doi:10.1172/JCI31537

32. Moncada S, Palmer RM, Higgs EA. 1991. Nitric oxide: physiology, pathophysiology, and pharmacology. Pharmacol Rev 43(2): 109-142.

33. Collins SJ. 1987. The HL-60 promyelocytic leukemia cell line: proliferation, differentiation, and cellular oncogene expression. Blood 70(5): 1233-1244

34. Bai SK, Lee SJ, Na HJ, Ha KS, Han JA, et al. 2005. $\beta$-Carotene inhibits inflammatory gene expression in lipopolysaccharide stimulated macrophages by suppressing redox-based NF- $\kappa \mathrm{B}$ activation. Exp Mol Med 37(4): 323-334. doi:10.1038/emm.2005.42

35. Shiratori K, Ohgami K, Ilieva I, Jin XH, Koyama Y, et al. 2005. Effects of fucoxanthin on lipopolysaccharide-induced inflammation in vitro and in vivo. Exp Eye Res 81(4): 422-428. doi: 10.1016/j.exer.2005.03.002 
36. Heo SJ, Yoon WJ, Kim KN, Ahn GN, Kang SM, et al. 2010. Evaluation of anti-inflammatory effect of fucoxanthin isolated from brown algae in lipopolysaccharide stimulated RAW 264.7 macrophages. Food Chem Toxicol 48(8-9): 2045-2051. doi: 10.1016/j.fct.2010.05.003

37. Chew BP, Park JS, Wong MW, Wong TS. 1999. A comparison of the anticancer activities of dietary $\beta$-carotene, canthaxanthin and astaxanthin in mice in vivo. Anticancer Res 19(3A): 1849-1853.

38. Niranjana R, Gayathri R, Mol SN, Sugawara T, Hirata T, et al. 2015. Carotenoids modulate the hallmarks of cancer cells. J Funct Foods 18(Part B): 968-985. doi: 10.1016/j.jff.2014.10.017

39. Kennedy AR, Krinsky NI. 1994. Effects of retinoids, $\beta$-carotene, and canthaxanthin on UV- and X-ray-induced transformation of C3H10t1/2 cells in vitro. Nutr Cancer 22(3): 219-232. doi: $10.1080 / 01635589409514348$

40. van den Berg H. 1999. Carotenoid interactions. Nutr Rev 57(1): 1-10.

41. Grolier P, Arais-Braesco V, Zelmire L, Fessi H. 1992. Incorporation of carotenoids in aqueous systems: uptake by cultured rat hepatocytes. Biochim Biophys Acta 1111(1): 135-138. doi: 10.1016/00052736(92)90283-R

42. Palozza P, Maggiano N, Calviello G, Lanza P, Piccioni E, et al.
1998. Canthaxanthin induces apoptosis in human cancer cell line. Carcinogenesis 19(2): 373-376. doi: 10.1093/carcin/19.2.373

43. Liu A, Pajkovic N, Pang Y, Zhu D, Calamini B, et al. 2006. Absorption and subcellular localization of lycopene in human prostate cancer cells. Mol Cancer Ther 5(11): 2879-2885. doi: 10.1158/1535-7163.MCT-060373

44. Sen CK, Packer L. 1996. Antioxidant and redox regulation of gene transcription. FASEB J10(7): 109-720.

45. Franco R, Cidlowski JA. 2009. Apoptosis and glutathione: beyond an antioxidant. Cell Death Differ 16(10): 1303-1314. doi: 10.1038/ cdd.2009.107

46. Nara E, Hayashi H, Kotake M, Miyashita K, Nagao A. 2001. Acyclic carotenoids and their oxidation mixtures inhibit the growth of HL-60 human promyelocytic leukemia cells. Nutr Cancer 39(2): 273-283. doi: 10.1207/S15327914nc392_18

47. Woodall AA, Lee SW, Weesie RJ, Jackson MJ, Britton G. 1997. Oxidation of carotenoids by free radicals: relationship between structure and reactivity. Biochim Biophys Acta 1336(1): 33-42. doi: 10.1016/ S0304-4165(97)00006-8

48. Burton GW, Ingold KU. 1984. $\beta$-carotene: an unusual type of lipid antioxidant. Science 224(4649): 569-573. doi: 10.1126/science.6710156 